\title{
Reduction of chlorinous odor by the combination of oxidation and ion-exchange treatments
}

\section{$\operatorname{AUTHOR}(\mathrm{S})$ :}

Echigo, S.; Itoh, S.; Ishihara, S.; Aoki, Y.; Hisamoto, Y.

\section{CITATION:}

Echigo, S. ... [et al]. Reduction of chlorinous odor by the combination of oxidation and ionexchange treatments. Journal of Water Supply: Research and Technology--AQUA 2014, 63(2): 106-113

\section{ISSUE DATE:}

2014-03

URL:

http://hdl.handle.net/2433/200270

\section{RIGHT:}

(OIWA Publishing 2014. The definitive peer-reviewed and edited version of this article is published in Journal of Water Supply: Research and Technology-AQUA Vol 63 No 2 pp 106-113 doi:10.2166/aqua.2013.205 and is available at www.iwapublishing.com; この論文は出版社版でありません。引用の際には出版社版をご確認ご利用ください。; This is not the published version. Please cite only the published version. 


\title{
Reduction of Chlorinous Odor by the Combination of Oxidation and Ion-Exchange Treatments
}

\author{
S. Echigo*, S. Itoh*, S. Ishihara**, Y. Aoki*** and Y. Hisamoto**** \\ * Graduate School of Engineering, Kyoto University, C1, Nishikyo, Kyoto 615-8540, Japan \\ (E-mail: echigo@urban.env.kyoto-u.ac.jp) \\ ** Kobelco Eco-Solutions Co., Ltd., 1-4-78, Wakihama-cho, Chuo, Kobe 651-0072, Japan \\ *** Ajinomoto Co., Inc., 1-1, Suzuki, Kawasaki, Kanagawa 210-8681, Japan \\ **** METAWATR Co. Ltd., 1, Fuji-cho, Hino, Tokyo 191-8502, Japan
}

\begin{abstract}
To better control chlorinous odor in tap water, we assessed the performance of the combination of oxidation (ozonation or advanced oxidation processes, AOP) and ion-exchange treatment. In this process, hydrophilic neutral fraction (a major DOM fraction) is converted to ionic species, and these ions and ammonium ion are effectively removed during ion-exchange processes. We found that each treatment process (e.g., oxidation alone or ion exchange alone) was effective for the reduction of chlorinous odor to some extent, but the chlorinous odor formation potential was lower when oxidation process and ion exchange were applied in series. The combination of AOP (ozone/vacuum ultraviolet treatment) at a high ozone dose and ion exchange (both cation and anion) was most effective, and the chlorinous odor formation potential was reduced to approximately 30 TON from more than 100 TON. Also, DOC and ammonium ion were effectively removed with this process. Compared with ozonation, AOP was more effective at higher ozone dose. The effectiveness of this process was also confirmed in continuous mode with pilot-scale experiment.
\end{abstract}

Keywords

Chlorinous odor, advanced oxidation, ion exchange, dissolved organic matter, ammonium ion, trichloramine

\section{INTRODUCTION}

Modern water supply system based on rapid sand filtration and chlorination has been a great success in improving public health, but it is also true that people are not fully satisfied with the current tap water quality. In a nation-wide survey in Japan, $37.5 \%$ of the population drinks tap water directly, and $21.3 \%$ demands more advanced drinking water treatment even with higher cost (Cabinet Office, Government of Japan 2008). One of the major complains on tap water quality is chlorinous odor, the odor caused from the reaction of chlorine and organic/inorganic compounds in water (Itoh et al. 2007). This is true even for the tap water treated with ozone/granular activated carbon (GAC) treatment and several major water utilities in Japan have already launched an effort to reduce chlorinous odor in tap water (e.g., Kawatani and Ishimoto 2009). Chlorinous odor is not a problem only in Japan. For example, in Western Australia, chlorinous odor is a major complaint from costumers (e.g., MacDonalds et al. 2009). Also, considerable research efforts have been devoted to the identification of compounds responsible for chlorinous odor worldwide (Froese et al. 1999; Freuze et al. 2005).

While not all the compounds responsible for chlorinous odor have been identified, trichloramine (Kajino et al. 1999) and $N$-chloroaldimines (Froese 1999; Freuze et al. 2005) are known as major contributors to chlorinous odor. Trichloramine can be produced both inorganic (i.e., ammonium ion) and organic nitrogen (e.g., free amino acids). Also, other compounds responsible for chlorinous odor including $\mathrm{N}$-chlroaldimines are formed from dissolved organic matter (DOM). Thus, the strict control of both ammonium ion and DOM is essential for the control of chlorinous odor. 
The problem on the control of ammonium ion and DOM responsible for chlorinous odor is that they are hydrophilic and low-molecular-weight compounds. In particular, ammonium ion is hard to remove even by membrane treatment including reverse osmosis. One may argue that ammonium ion can be oxidized biological activated carbon. However, the performance of this system is temperature dependant and its control at very low concentration (i.e., a few $\mu \mathrm{g} / \mathrm{L}$ level) is not an easy task.

The purpose of this study is to better control ammonium ion and DOM with the combination of oxidation (ozonation or advanced oxidation processes, AOP) and ion-exchange treatment. In this process, hydrophilic neutral fraction (a major DOM fraction) is converted to ionic species, and these ions and ammonium ion are effectively removed during ion-exchange process. In this paper, the performance of this new system in both bench scale and pilot scale is discussed.

\section{MATEIALS AND METHODS}

This study consists of two parts. First, a series of bench-scale experiments were performed to evaluate the effectiveness this new treatment process. For this part, the test water was collected from Yodo River at Hirakata bridge (Osaka, Japan) and used after filtration by mixed cellulose ester membrane (0.45 $\mu \mathrm{m}$, Advantec). Ozonation and ozone/vacuum ultraviolet (VUV) treatment (hereinafter referred to as AOP) were used as oxidation processes. Both treatments were performed in semi-batch mode. In the second part of this study, pilot-scale experiments were performed in the Kunijima water purification plant of Osaka City to confirm the effectiveness of this process in continuous mode. For both parts, all the chemicals used were purchased from Wako (Analytical grade or better) unless otherwise noted. For the preparation of standard and stock solutions, ultrapure water purified by a Milli-Q Academic A10 system (Millipore) was used.

\section{Bench-scale experiments}

This part consists of three sets of experiments: (1) reduction of chlorinous odor by oxidation processes (ozonation or AOP); (2) reduction of chlorinous odor by ion-exchange treatments; (3) reduction of chlorinous odor by the combination of oxidation and ion exchange.

Reduction of chlorinous odor by oxidation processes. Ozone gas was produced from ultrapure oxygen by an ozone generator (AZH-3S, Hamamatsu Vegetable). For AOP, a vacuum ultraviolet (VUV) lamp with principal wavelengths of 254 and $185 \mathrm{~nm}$ (AY-11, Photoscience Japan) was employed. The path length of the UV reactor was $37.5 \mathrm{~mm}$, and this reactor was connected to an ozone contactor (total volume $=4.0 \mathrm{~L}$ ) by PTEF tubes. The test solution was recirculated by a magnet pump (IWAKI) between the UV reactor and the ozone contactor at a flow rate of $4.2 \mathrm{~L} / \mathrm{min}$.

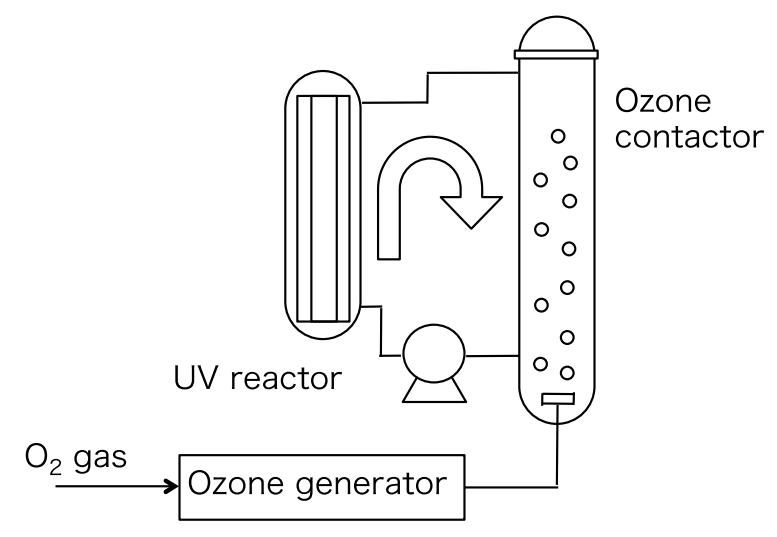


Figure 1. Schematic of the bench-scale reactor for ozonation and AOP.

Reduction of chlorinous odor by ion-exchange treatments. Anion and cation exchange treatments were performed successively at a flow rate of $60 \mathrm{~mL} / \mathrm{min}$ in this order when both treatments were applied. For anion exchange, DIAION PA308 (Mitsubishi Chemical, Japan) was used. For cation exchange, type $\mathrm{X}$ zeolite was employed. These ion exchangers were washed with Milli-Q water, regenerated with $3 \mathrm{~L}$ of $10 \% \mathrm{NaCl}$ solution, and washed again with $5 \mathrm{~L}$ of Milli-Q water before treatment. The test water was fed to a glass column ( $\phi 40$ x $500 \mathrm{~mm}$, Kiriyama Glass) packed with an ion exchanger by a Master Flex pump (Model 7518-00) continuously.

Chlorinous odor reduction by the combination of oxidation and ion-exchange treatment. The combination of oxidation (ozonation or AOP) and ion-exchange treatment (anion and/or cation exchange) was applied to the test water collected from Yodo River (sampled at Hirakata bridge). Two different ozone doses ( 2 and $10 \mathrm{mg} / \mathrm{L}$ ) were applied to both ozonation and AOP. The same reactors, VUV lamp, and ion-exchange resins were used as described previous subsections.

\section{Pilot-scale experiments}

The schematic of the pilot-scale plant is shown in Figure 2. The flow rate in ozone contactors, ozone reactor, and GAC column was $1.0 \mathrm{~m}^{3} / \mathrm{h}$, and a part of effluent from GAC column or directly the ozone reactor was fed to the cation exchange column at a flow ate of $0.5 \mathrm{~m}^{3} / \mathrm{h}\left(\mathrm{SV}=5 \mathrm{~h}^{-1}\right)$. Then, The source water for this plant was the water after sand filtration taken from the actual treatment facility. Two different ozone doses (1.5 and $3.0 \mathrm{mg} / \mathrm{L})$ were applied to both ozonation and AOP. Thus, this experiment consists of four runs (note: the conditions for ion-exchange treatment was fixed: flow rate, $60 \mathrm{~mL} / \mathrm{min} ; \mathrm{SV}, 7.2 \mathrm{~h}^{-1}$ ). To run these four conditions, it took two days. The experiment was repeated four times (i.e., total 16 runs) from December 2011 to February 2012.

For the first and second ozone contactors (i.e., the first and second columns), VUV lamps with principle wavelengths of 254 and 185 nm (QGL65-31, Iwasaki, Japan) were installed. For the ozone reactor (i.e., the third column), a conventional low-pressure mercury lamp (QGL65W-2, Iwasaki, Japan) was used because the presence of dissolved ozone at a sufficient concentration was expected.

Ion-exchange treatment was conducted in the following order: cation exchange and then anion exchange. This order was different form the bench-scale experiments. This was because of the limited configuration in the pilot plant. Lewatit MnoPlus S 100 cation exchange resin (Lanxess, Germany) and DIAION PA308 were used for cation and anion exchange, respectively. The former was regenerated with $62.5 \% \mathrm{H}_{2} \mathrm{SO}_{4}$ (Nankai Chemical) and the latter was regenerated in the same manner in the bench-scale experiment. 


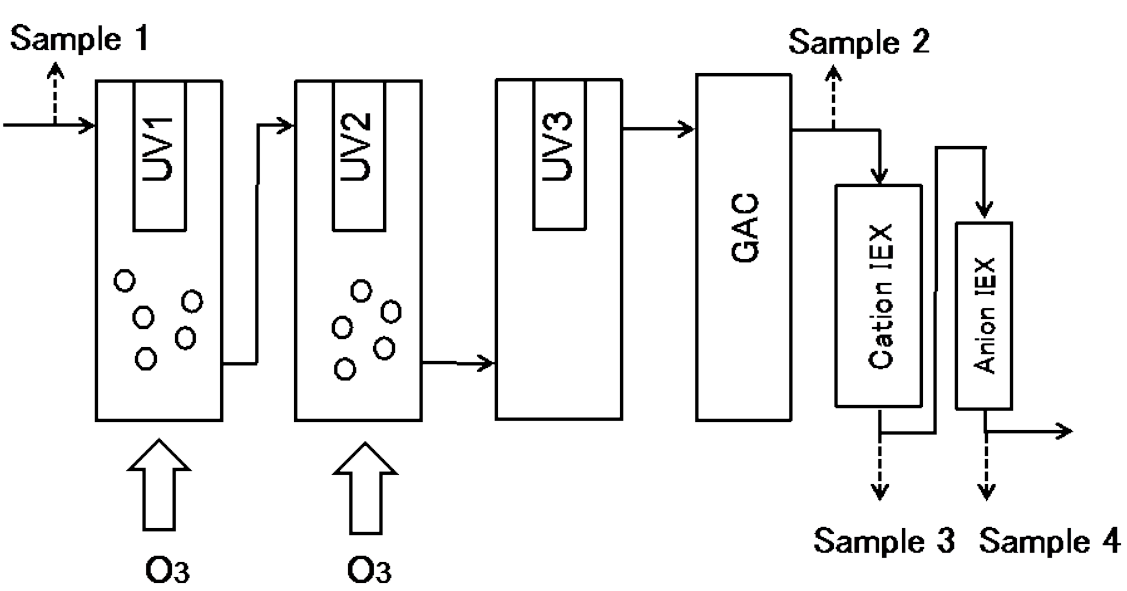

Figure 2. Schematic of the pilot-scale plant.

\section{Analytical methods}

Chlorinous odor formation potential of each sample was measured after chlorination for 24 hours. The residual free chlorine after 24 hours was controlled at $1.0 \mathrm{mg} / \mathrm{L}$. Then, the odor intensity was measured by the triangle sensory test (Yanagibashi et al. 2009). The odor strength of $1 \mathrm{mg} / \mathrm{L}$ chlorine solution is approximately 20 TON. For the bench-scale experiments, the solution $\mathrm{pH}$ before chlorination was not adjusted, but it was adjusted to neutral $\mathrm{pH}$ for the samples from the pilot plant as the cation-exchange resin was in proton form and the effluent $\mathrm{pH}$ was around 3 . In addition to odor intensity, trichloramine $\left(\mathrm{NCl}_{3}\right)$ concentration was measured by headspace-GC/MS analysis developed by Kosaka et al. (2010) with minor modification as one of the major compounds causing chlorinous odor. The quantification limit of this method was $5 \mu \mathrm{g}$ as $\mathrm{Cl}_{2} / \mathrm{L}$.

Ammonium (Kuo et al. 2005) and bromate ions were monitored by ion chromatography with postcolumn derivatization. For these analyses, $o$-phthalaldehyde and $o$-dianisidine (TCI) were the derivatizing reagents, respectively. Their quantification limits were $0.4 \mu \mathrm{g}$ as $\mathrm{N} / \mathrm{L}$ and $0.3 \mu \mathrm{g} / \mathrm{L}$, respectively.

\section{RESULTS AND DISCUSSION}

\section{Effect of ozonation and AOP on chlorinous odor}

Chlorinous odor formation potentials after ozonation and AOP (i.e., ozone/VUV treatment) are shown in Figure 3. Compared with the control sample (i.e., chlorination only), chlorinous odor formation potential decreased by $40 \%$ and $30 \%$ for ozonation and AOP, respectively. AOP was less effective than ozonation probably due to the formation of ammonium ion (i.e., a precursor of trichloramine) during the decomposition process of dissolved organic matter. Higher ammonium ion concentration was observed for AOP. For example, at an ozone dose of $5 \mathrm{mg} / \mathrm{L}$, ammonium ion concentration was $48 \mu \mathrm{g} / \mathrm{L}$ after AOP, while it was $30 \mu \mathrm{g} / \mathrm{L}$ after ozonation. One may argue that this is a drawback of AOP, but if combined with ion-exchange treatment, ammonium ion will be effectively removed. Also, higher ozone dose $(10 \mathrm{mg} / \mathrm{L})$ did not resulted in lower chlorinous odor formation potential. This indicates that some of the reaction products still serve as precursors of chlorinous odor (e.g., ammonium ion and free amino acids) after intensive oxidation, and they are not readily converted to inert compounds to chlorine.

\section{Effect of ion exchange on chlorinous odor}

The effect of ion-exchange treatment on the chlorinous odor formation potential without oxidation 
process is shown in Figure 4. Compared with the control (i.e., chlorination only, odor strength 129 TON), chlorinous odor formation potential after anion exchange decreased to 100 TON. The effect of anion exchange alone seemed to be limited. Also, anion exchange expected to simplify the matrix of odor compounds by removing organic precursors. This may have made the smell of trichloramine clearer (i.e., greater odor strength).

The chlorinous odor formation potential decreased to 73 TON by cation-exchange treatment (note that ammonium ion concentration ranged from 15 to $89 \mu \mathrm{g} / \mathrm{L}$ for the control samples). This suggests that removal of ammonium ion and organic bases is effective for the control of chlorinous odor, but the complete removal of chlorinous odor is still impossible by this unit operation alone. That is, several different odor compounds are produced from different types of precursors. To resolve this situation, both organic (DOM) and inorganic (ammonium ion) precursors have to be controlled. Indeed, when both anion and cation exchange processes were applied, the chlorinous odor formation potential decreased to $47 \mathrm{TON}$. The reduction of odor strength by cation and anion exchange treatments appeared to be additive (i.e., the reduction by cation exchange + the reduction by anion exchange $=$ the reduction by the sequential ion exchange treatment). This indicated that the smell of compounds produced from the reaction of chlorine and ammonium ion and that from the reaction of chlorine and organic anions are similar. This may imply that trichloramine was the major compounds responsible for chlorinous odor in this experiment.

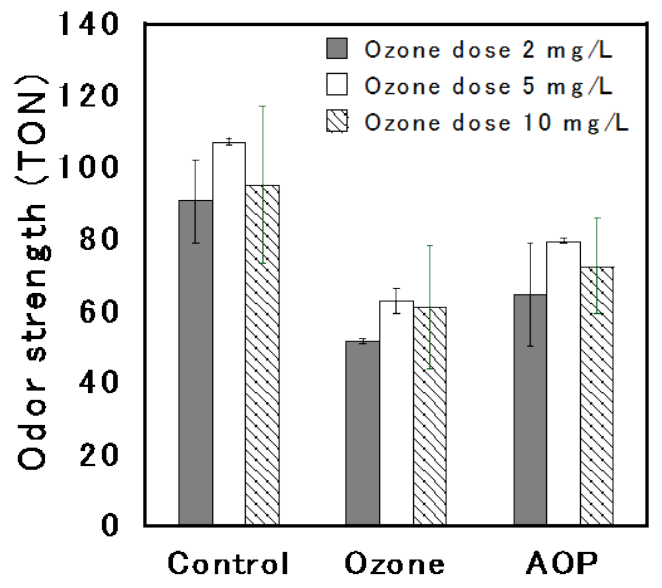

Figure 3. Effect of oxidation processes on chlorinous odor formation potential (Control: chlorination alone, Ozone: chlorination after ozonation, AOP: chlorination after AOP).

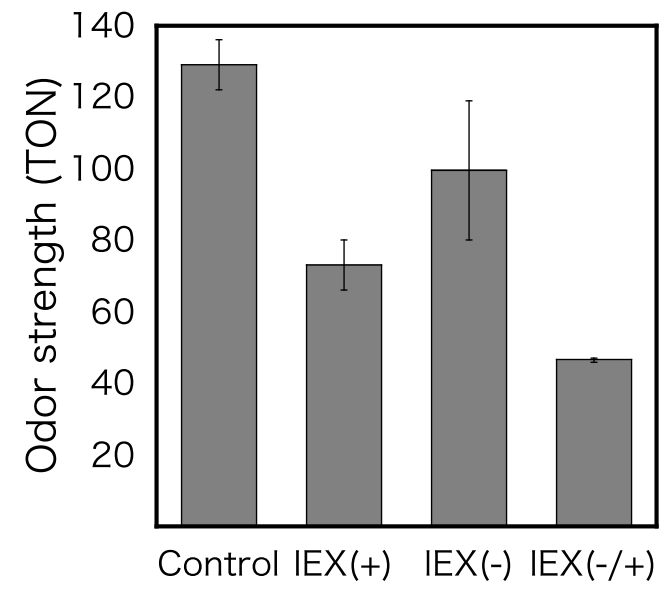

Figure 4. Effect of ion exchange on chlorinous odor formation potential (Control: chlorination alone, IEX: chlorination after ion exchange, the "+" and "-_"signs indicate cation and anion exchange, respectively).

\section{Control of chlorinous odor by the combination of oxidation and ion-exchange treatment}

The chlorinous odor formation potentials after the combination of oxidation and ion-exchange treatment is shown in Figures 5 and 6. The sequential treatment by AOP at an ozone dose $10 \mathrm{mg} / \mathrm{L}$, cation exchange, and anion exchange was most effective with respect to the odor strength after chlorination (32 TON). For the combination with ozonation (i.e., without VUV radiation) and ionexchange treatment, the change of ozone dose showed no major impact (42 and 40 TON for ozone dose of 2 and $10 \mathrm{mg} / \mathrm{L}$, respectively). On the other hand, increasing ozone dose for AOP improved chlorinous odor formation potential (Figure 6). This indicated that organic precursors were effectively converted to ionic species when AOP was applied at high ozone dose. 
During oxidation process, relatively high concentration of bromate ion was observed (Table 1). However, it was completely removed by anion exchange. Also, the combination of cation and anion exchange was very effective for the reduction of chlorine demand and DOC. Also, it is of note that a higher trichloramine concentration was observed after oxidation and anion exchange. A possible reason for this result is the decrease of $\mathrm{pH}$ after anion exchange.

These results let us conclude that AOP (i.e., ozone/VUV treatment) effectively ionizes DOM in source water, and the combination of AOP and ion-exchange treatment is an appropriate and rational way to control chlorinous odor in drinking water treatment.

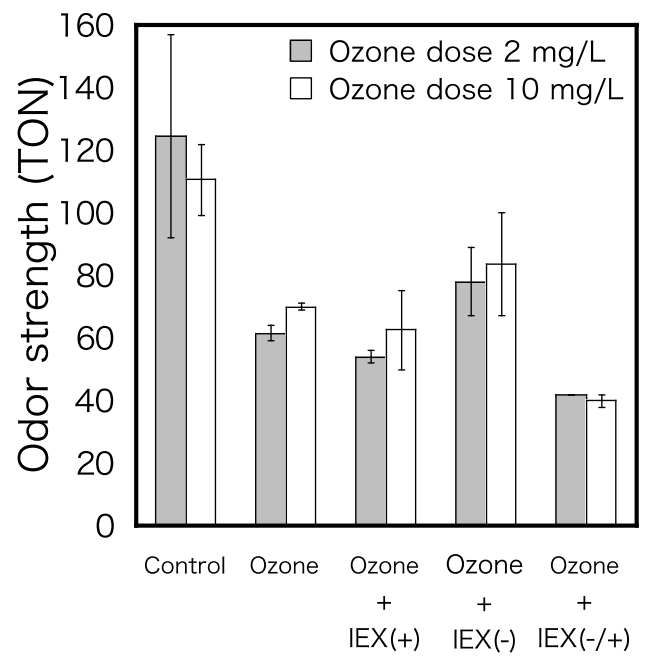

Figure 5. Effect of the combination of ozonation and ion exchange on chlorinous odor formation potential (See the captions of Figures 3 and 4 for the definition of the labels).

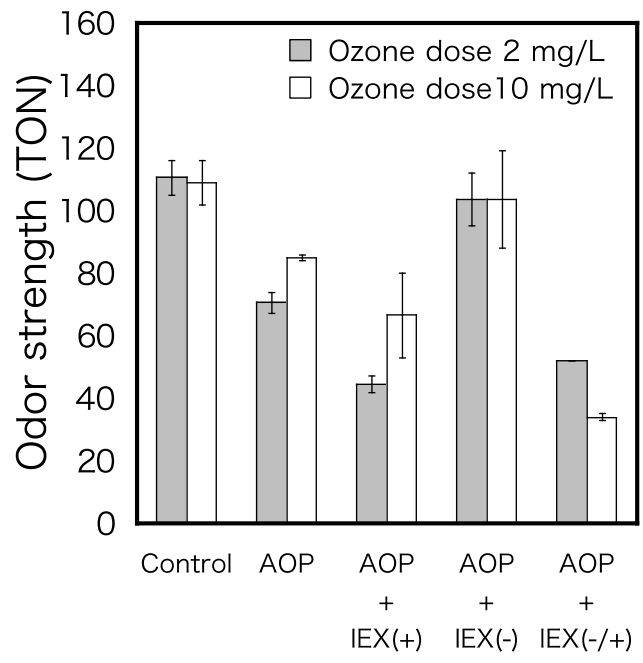

Figure 6. Effect of the combination of AOP and ion exchange on chlorinous odor formation potential (See the captions of Figures 3 and 4 for the definition of the labels).

In addition to the ozone dose commonly used in actual treatment practice, the combination of AOP and ion-exchange was applied with an extremely high ozone dose to evaluate the lowest achievable odor strength. For this experiment, ozone dose was set to $200 \mathrm{mg} / \mathrm{L}$. At this ozone dose, most DOM was mineralized and remaining DOC was in the range of 0.1 to $0.2 \mathrm{mg} / \mathrm{L}$. The DOC level further decreased below $0.1 \mathrm{mg} / \mathrm{L}$ by anion exchange. The results of odor strength are shown in Figure 7. AOP alone reduced the odor strength down to 35 TON. In addition to the decomposition of organic precursors, partial oxidation of ammonium ion may have contributed to this low odor strength under this extreme oxidation condition. The odor strength further decreased to 24 TON by the following ion-exchange treatment. As mentioned above, since the odor strength of $1 \mathrm{mg} / \mathrm{L}$ chlorine solution is approximately $20 \mathrm{TON}$, our result showed that the combination of AOP and ion exchange could remove all the precursors of chlorinous odor other than that of chlorine itself.

Table 1. Water quality after the combination of oxidation and ion-exchange treatment. 


\begin{tabular}{|c|c|c|c|c|c|c|}
\hline & & $\begin{array}{c}\mathrm{NH}_{4}^{+} \\
(\mu \mathrm{g}-\mathrm{N} / \mathrm{L})\end{array}$ & $\begin{array}{c}\mathrm{NCl}_{3} \\
\left(\mu \mathrm{g}-\mathrm{Cl}_{2} / \mathrm{L}\right)\end{array}$ & $\mathrm{DOC}(\mathrm{mg}-\mathrm{C} / \mathrm{L})$ & $\begin{array}{l}\mathrm{BrO}_{3}^{-} \\
(\mu \mathrm{g} / \mathrm{L})\end{array}$ & $\begin{array}{c}\text { Chlorine } \\
\text { demand } \\
\left(\mathrm{mg}-\mathrm{Cl}_{2} / \mathrm{L}\right)\end{array}$ \\
\hline \multirow{5}{*}{ Ozonation } & Control & 84 & 42 & 1.6 & $\mathrm{n} / \mathrm{d}$ & 2.1 \\
\hline & Ozone & 76 & 32 & 1.5 & 19 & 2.1 \\
\hline & Ozone $+\operatorname{IEX}(+)$ & 6 & 26 & 1.4 & 18 & 1.2 \\
\hline & Ozone+IEX(-) & 72 & 133 & 0.3 & $\mathbf{n} / \mathbf{d}$ & 1.0 \\
\hline & Ozone $+\operatorname{IEX}(-/+)$ & 5 & 28 & 0.3 & $\mathbf{n} / \mathbf{d}$ & 0.5 \\
\hline \multirow{5}{*}{ AOP } & Control & 63 & 26 & 1.7 & $\mathbf{n} / \mathbf{d}$ & 2.3 \\
\hline & AOP & 83 & 47 & 0.8 & 6 & 2.3 \\
\hline & AOP+IEX(+) & 10 & 19 & 0.7 & 5 & 1.2 \\
\hline & AOP+IEX(-) & 78 & 124 & 0.1 & $\mathbf{n} / \mathbf{d}$ & 1.3 \\
\hline & AOP $+\operatorname{IEX}(-/+)$ & 5 & 33 & 0.1 & $\mathbf{n} / \mathbf{d}$ & 0.4 \\
\hline
\end{tabular}

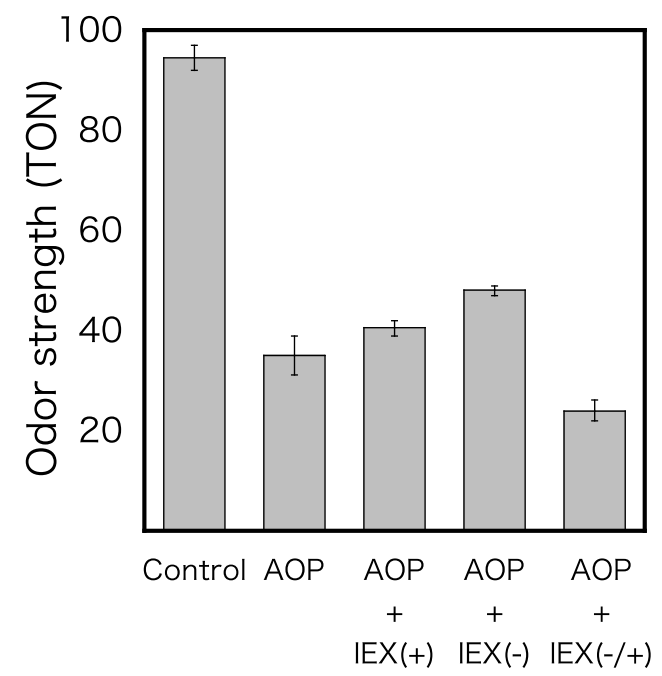

Figure 7. Effect of the combination of oxidation and ion exchange under extremely high ozone dose $(200 \mathrm{mg} / \mathrm{L})$ on chlorinous odor formation potential (See the captions of Figures 3 and 4 for the definition of the labels).

\section{Pilot-scale experiments (continuous system)}

Chlorinous odor formation potential after each treatment step (rapid sand filtration, oxidation (i.e., ozonation or AOP), GAC, cation exchange, and anion exchange) in the pilot-scale experiment is shown in Figure 8 for both ozone doses of 1.5 and $3.0 \mathrm{mg} / \mathrm{L}$. The combination of AOP at an ozone dose of $3 \mathrm{mg} / \mathrm{L}$ and ion exchange (both cation and anion exchange) was most effective among the conditions tested. Under this condition, the lowest odor strength observed was 21 TON (Note that the formation potential of the control samples were lower than those in the bench-scale experiments because the feed water was pretreated by intermediate ozonation). This result shows that the combination of oxidation and anion exchange is effective in continuous mode. Also, the result confirms that conventional $\mathrm{O}_{3} / \mathrm{GAC}$ does not remove chlorinous odor formation potential.

Since ammonium ion concentration was low throughout the experiment (5-23 $\mu \mathrm{g} / \mathrm{L})$, the effect of cation exchange was not clear. At higher ammonium concentration, relative importance of this process would increase. 


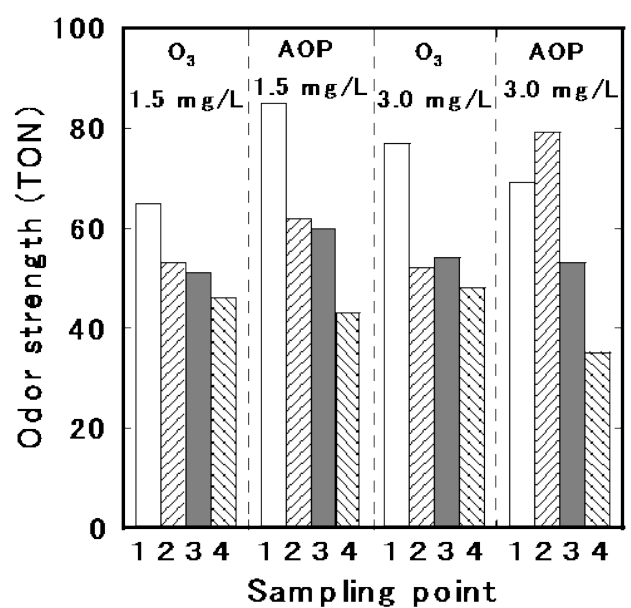

Figure 8. Chlorinous odor formation potential along the pilot-scale treatment system with the combination of oxidation and ion-exchange treatment (1: After rapid sand filtration, 2: after oxidation, 3: after cation exchange, 4: after anion exchange. Each bar is a geometric mean of multiple evaluations ( $\mathrm{n}=3$ or 4$)$ ).

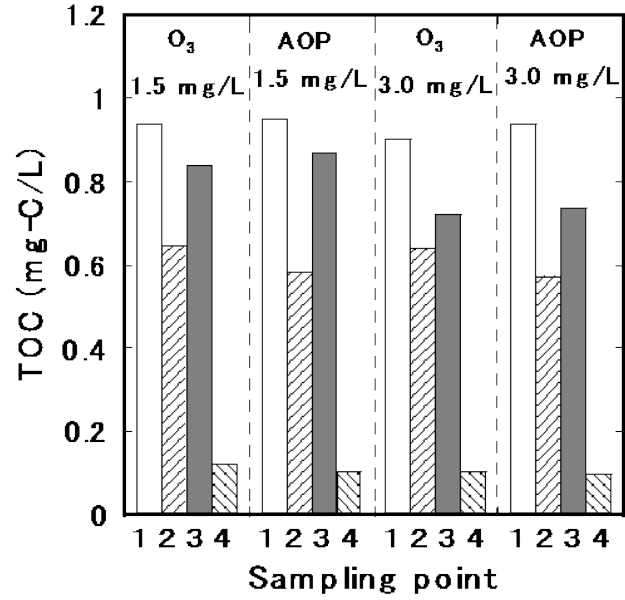

Figure 9. TOC profile along the pilotscale treatment system with the combination of oxidation and ionexchange treatment (See Figure 2 and the caption of Figure 8 for the definition of labels).

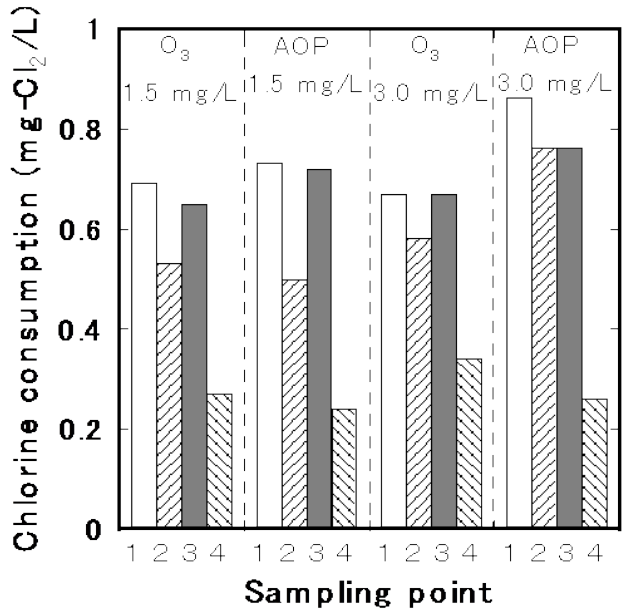

Figure 10. The profile of chlorine consumption along the pilot-scale treatment system with the combination of oxidation and ion-exchange treatment (See Figure 2 and the caption of Figure 8 for the definition of labels).

Figures 9 and 10 show TOC and chlorine demand at each treatment step. In some cases, higher TOC and/or chlorine demand were observed after cation exchange. This could be the bleeding of organic compounds from ion-exchange resin or pipes. With anion-exchange treatment, TOC level decreased dramatically (below $0.1 \mathrm{mg} / \mathrm{L}$ when combined with AOP). A similar trend was observed for chlorine demand. These results imply that anion exchange treatment is an effective way to remove organic compounds that are difficult to control by the conventional $\mathrm{O}_{3} / \mathrm{GAC}$ treatment. While our new treatment process was designed primarily for chlorinous odor control, this process will be useful for the reduction of hydrophilic micropollutants and the control of disinfection byproducts. 


\section{CONCLUSIONS}

The combination of oxidation process (ozonation or AOP) and ion exchange (cation and/or anion exchange treatments) were applied for controlling chlorinous odor. The combination of AOP at a high ozone dose and ion exchange (both cation and anion) was most effective, and the chlorinous odor formation potential was reduced to 32 TON from more than 100 TON. DOC and ammonium ion were effectively removed with this process. Compared with ozonation, AOP was more effective at higher ozone dose. The effectiveness of this process was also confirmed in continuous mode with pilot-scale experiment. Thus, it was concluded that the combination of AOP and ion-exchange treatments was an effective technology for controlling chlorinous odor. This process was also suitable for the control of DOC, chlorine demand and bromate ion. The combination of ozonation and ion exchange was also effective for chlorinous odor and DOC removal. Thus, upgrading the current system successively would be a realistic and effective strategy.

\section{ACKNOWLEDGEMENTS}

Financial support was provided in part by Osaka City Waterworks Bureau, JSPS KAKENHI Grant Number 21360257, and Health Labour Sciences Research Grant.

\section{References}

Cabinet Office, Government of Japan 2008 National Survey on Water, http://www8.cao.go.jp/survey/h20/h20-mizu/index.html, accessed on August 31, 2012.

Freuze, I., Brosillon, S., Laplanche, A., Tozza, D., Cavard, J. 2005 Effect of chlorination on the formation of odorous disinfection by-products. Water Res., 39(12): 2636-2642.

Froese, K., Wolanski, A., Hrudey, S. 1999 Factors governing odorous aldehyde formation as disinfection by-products in drinking water. Water Res., 33(1):1355-1364.

Itoh, S., Shiro, S., Hirayama, N., Echigo, S., Ohkochi, Y. 2007 Psychosocial considerations on strategies for improving customers' satisfaction with tap water based on causal modeling. J. Japan Water Works Assoc., 76(4): 25-37.

Kajino, M., Morizane, K., Umetani, T., Terashima, K. 1999 Odors arising from ammonia and amino acids with chlorine during water treatment. Water Sci. Technol., 40(6): 107-114.

Kawatani, Y., Ishimoto, T. 2009 Process after introduction of advanced water purification system and future technology meeting customer demands in Osaka City. Environ. Snit. Eng. Res., 23(3): 10-15.

Kosaka, K., Seki, K., Kimura, N., Kobayashi, Y., Asami M. 2010 Determination of trichloramine in drinking water using headspace gas chromatography/mass spectrometry. Water Sci. Technol.: Water Supply, 10(1): 23-29.

Kuo, C.T., Wang, P.Y., and Wu, C.H. 2005 Fluorometric determination of ammonium ion by ion chromatography using postcolumn derivatization with $o$-phthaldialdehyde. J. Chromatogr. A, 1085:91-97.

McDonald, S., Lethorn, A., Loi, C., Joll, C., Driessen, H., and Heitz, A. 2009 Determination of odour threshold concentration ranges for some disinfection by-products for an Australian panel, Water Sci. Technol., 60(10), 2493-2506.

Yanagibashi, Y., Quan, D., Itoh, S., Echigo, S., Miyamoto, T., Ohkouchi, Y. 2009 Application of a triangle test to the measurement of threshold odor numbers (TONs) in the water supply. J. Japan Water Works Assoc., 78(1): 2-12. 